\title{
A Limited Investigation into the Significance of the Site of the First Lesion in Leprosy
}

\author{
Dr. I. A. SUSMAN, M.в., CH.B., D.P.H., D.T.M. \& H. \\ Leprologist, Republic of Togo
}

\section{INTRODUCTION}

The paths by which Mycobacteria leprae enter the body have up to now been difficult to trace; the inability to grow the bacillus outside the human body has handicapped such investigations concerning transmission.

Muir ${ }^{1}$ has stated that there are many instances of the disease having developed at sites of accidental inoculation.

We have as yet no proof of infection through the gastro-intestinal tract.

The possibility of insect transmission has been put forward (Moiser ${ }^{2}$, Spickett ${ }^{3}$ ).

However, the skin as being the portal of entry is still the most widely held view and it is generally believed that skin to skin contact is the most frequent means of acquiring bacilli.

In recent years, Weddel and Palmer ${ }^{4}$ have produced evidence to show that $M$. leprae can be disseminated by the blood stream and suggested that the organism does not enter the skin merely by contact or inunction but possibly via the respiratory or alimentary tracts. There was, however, no evidence put forward to support or refute this latter suggestion.

If the portal of entry of $M$. leprae is truly the skin, then the localisation of the first lesion of leprosy shown in the skin should be related to the point of contact in the affected individual. That is, the site of the first cutaneous manifestation of the disease should be at the point of contact of the infected individual with the contaminated skin of the infector.

In West Africa, almost every infective girl or woman has the opportunity for close and prolonged contact with children-either her own, those of related families or even unrelated families. This is because of the national custom of the females carrying the children on their backs, usually naked, and over a long period.

Although it has been the personal experience of the writer to obtain usually not more than $12 \%$ of positive answers to the question of knowledge by the patient of contact with another leprosy sufferer, it has generally been found that contact with an infected mother accounts for about $25 \%$ of such cases. A further $20 \%$ approximately attribute their disease to contact with an infected sister $\left(\operatorname{Susman}^{5}\right)$.

Contact then between infective patients with leprosy and healthy persons appears to be the most important even if not the sole method of spread of the disease. This contact is usually direct, though may possibly be indirect, e.g., through infected clothes, bedding, etc. It is generally believed that close and continued contact is most favourable for transmission; in highly susceptible persons, however, contact of even short duration may result in the disease.

As already stated, the entry of the bacillus via the skin appears to be the most important mode of infection. The following investigation was undertaken in an attempt to find out whether further weight could be given to the assumption.

INVESTIGATION

Five hundred and ninety-seven leprosy patients, consisting of 345 men and 252 women, were closely questioned as to the localisation of the very first patch or mark of leprosy which appeared on their body. Only those who appeared to be explicit in their description were considered, doubtful answers being excluded. Thus, in fact, the first single lesions of 355 leprosy patients (198 men and 157 women) were taken into account. The patients were all from the northern regions of Togo. The following were the results obtained:- 


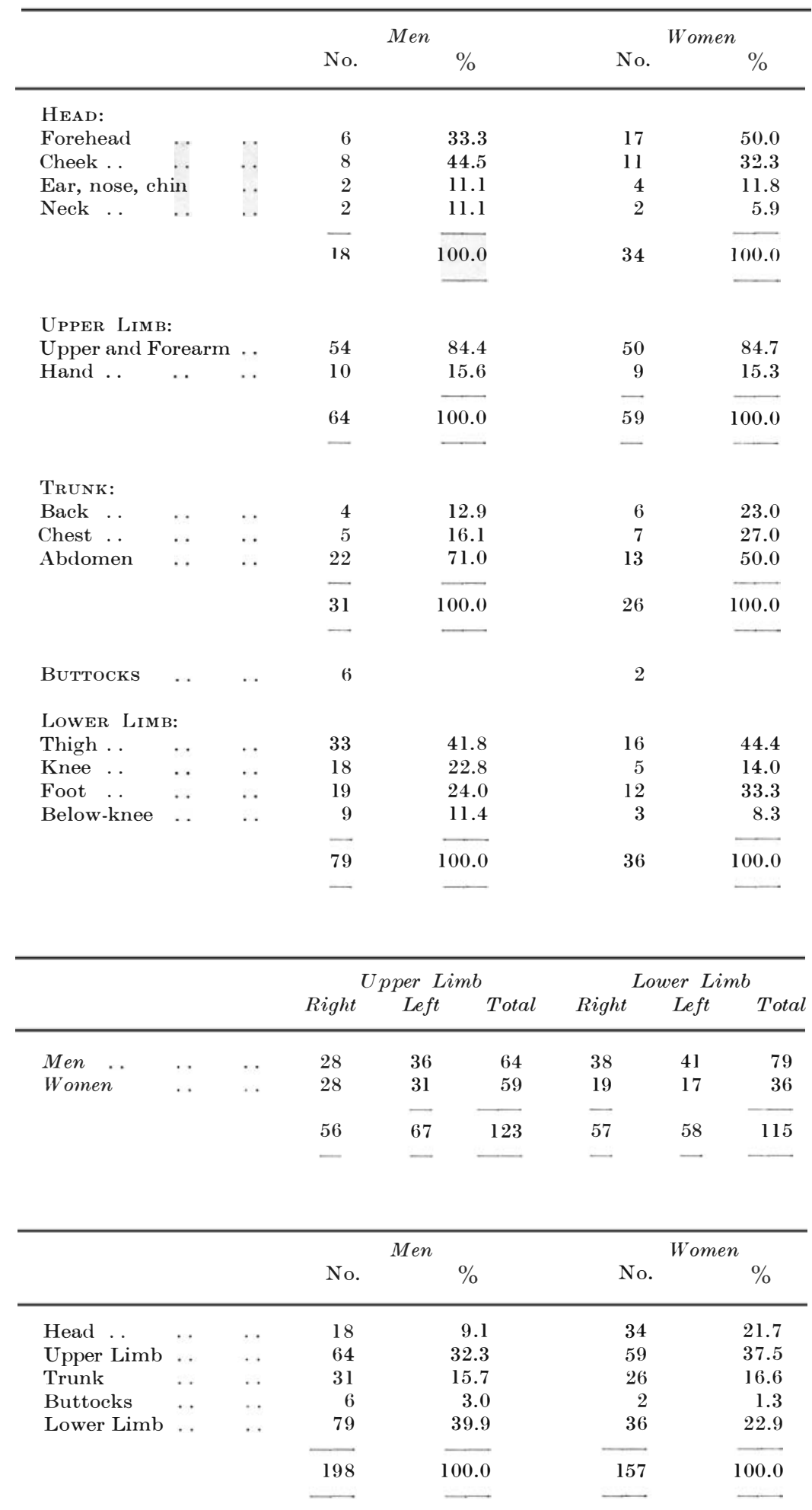




\section{RESULTS}

From the above tables, it can be seen that either the lower or upper limbs provide the site for the greatest number of first lesions. In men, the lower and upper limbs account for approximately $40 \%$ and $32 \%$ of the first lesions respectively, whereas in women these percentages are approximately 23 and 37 respectively. In both men and women, the trunk accounts for around $16 \%$ of first lesions, being the third site of importance in the men and the fourth in the women. In the men, the head produced nearly $9 \%$ of the first lesions, the fourth site of importance, and in the women the head was the locality of nearly $22 \%$ of first lesions, being in them the third site of impor-
Furthermore, the tables show that in the head, the forehead and cheek each account for more than one-third of lesions; in women, in fact, the forehead accounted for half of such lesions. In the upper limb, over $80 \%$ of the lesions were upper- and fore-arm as opposed to hand lesions. In the trunk, the abdomen was the main site of first lesions, then the chest and, least important, the back. The thighs accounted for over $40 \%$ in the lower limbs, then the feet, the knees, and below-knees in diminishing frequency.

The following shows a comparison of the above results with those obtained in adults by Horton and Povey ${ }^{6}$ in their investigation in South India:-

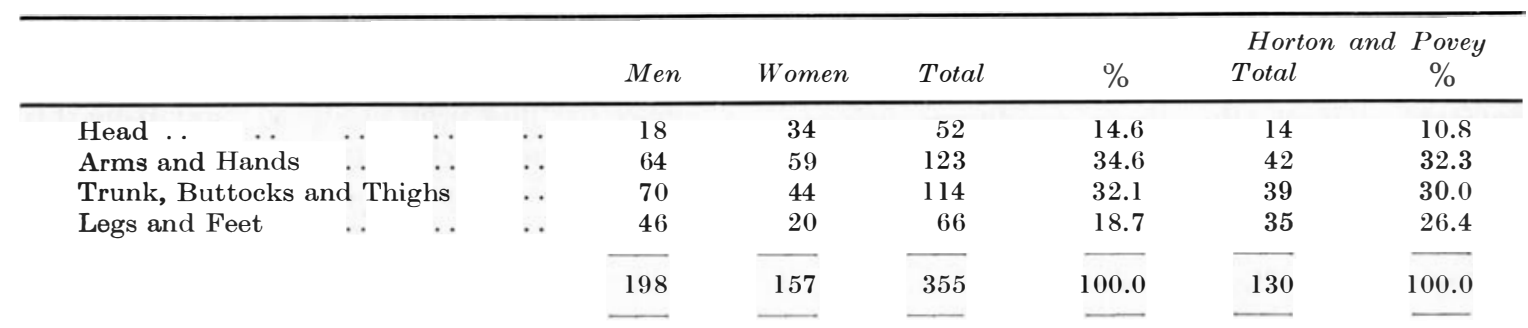

tance. In both sexes, the buttocks was the site of least importance producing only few first lesions, in the men $3 \%$ and in the women about $1 \%$.

It has been observed from personal experience that women tend to be more conscious of lesions on the face than men and also tend to draw attention to lesions on the buttocks and thighs less frequently than do men, and unless specifically examined for such lesions these can be missed. In this investigation, reliance was placed on the patient's own story and it is probable that these facts might explain the increased number of first lesions accounted for on the head in women and the lesser number on the lower limbs and buttocks.

It can also be seen from the above tables that in both sexes there was no significant difference in the localisation of first lesions on the 2 sides, that is in the right and left of either upper or lower limbs. Horton and Povey ${ }^{6}$ showed no difference in the distribution of lesions in the 2 hands in their series.
This table shows a very similar comparison in the 2 investigations and fits in with the facts that, in both, the children are usually naked and in close contact with their mothers by being carried on the back or are handled to a great extent by their mothers (or sisters).

Correlation of above findings with the facts concerning contacts

In Togo, as in many other countries, it is the custom for babies to be carried on the backs of their mothers from 8 to 10 days after birth until the child is 2 to 3 years old. Often, this period is extended until the child reaches 5 years of age, especially where the mother has no younger children. It is deemed a pleasure for the mother to carry the infant in this way when she has no other babies.

In northern Togo where this investigation was undertaken, the child is generally naked when carried. The mother may be naked also above her waist with a cloth enclosing the child's body around her own. In many cases, however, some 
cloth is worn by the mother, in which cases the child's trunk is not, therefore, always in direct contact with the bare skin of the mother. Often, also, the legs of the child are held directly against the skin of the mother's side and back under the mother's cloth, the front of the infant's trunk being directly against the mother's bare back only when the upper part of the mother's body is quite nude. When the mother is thus unclothed the child's bare arms are directly in contact with the mother's lower chest but otherwise the arms may be outside or inside the mother's cloth. Even when the mother does cover the upper part of her body, the baby's head (cheek or forehead) is in contact with the bare back of the neck of the mother, especially in the bigger children.

Hence, in the north of Togo the most likely areas of contact, the above conditions being considered prevailing in the mother and infant, would appear to be, in order of diminishing frequency, the legs (especially the thighs) closely followed by the arms (especially the upper- and fore-arms), then the trunk (principally the abdomen) and then the head (mainly the forehead and cheeks). The buttocks are obviously not involved much in this question of skin to skin contact.

Thus, the findings shown in the above tables appear to fit in largely with these facts concerning the actual areas of contact between mother and child. Furthermore, it has been stated that the mother/child contact appears to be the most important one ascertained in the history of contacts. Also, sister/child may be the second important contact relationship, and it is a fact that of ten the infant is carried by its older sister for a large part of the time when not carried by the mother. This is the case even where the sister is only a few years older and, of course, the carrying of the infant is executed in the same manner.

Rogers and Muir ${ }^{7}$ have stated specifically that children are particularly liable to infection and this has been supported by many leprologists including Cochrane ${ }^{8}$, Doull ${ }^{9}$ and Chaussinand ${ }^{10}$.
Other field workers have agreed with this postulate $\left(\right.$ Languillon $^{12}$, Susman $\left.^{5}\right)$. Browne ${ }^{13}$ states that 'No age is exempt from leprosy', but also 'In comparable communities, a higher proportion of leprosy infection in the younger age groups will be disclosed by examination of all children'. Other workers, however, have refuted the fact 'that the majority of persons acquire leprosy ... before the age of 20. .' (Mohamed $\left.\mathrm{Ali}^{11}\right)$.)

Recent work (Spickett ${ }^{14}$ ) has produced evidence strongly suggesting that there are human genetic factors involved in the epidemiology of leprosy. Such genetic factors were considered as playing an important role in the determination of the susceptibility to leprosy by previous workers such as Aycock, Rotberg, Steiniger and Kinnear Brown. However, although strong evidence has now been produced supporting this possibility and further study is needed in this field, one must not lose sight of the fact that environmental factors play a very important part in relation to leprosy.

\section{SUMMARY}

From this very limited investigation into the localisation of the first lesions appearing in leprosy patients in northern Togo, there is an indication that the sites of such lesions, when ascertained as accurately as possible, show close correlation with the actual sites of contact of the patient, generally with the mother in infancy and early childhood. This, therefore, lends support to the generally held opinion of portal of entry of the leprosy bacillus through the skin brought about principally by skin to skin contact.

\section{ACKNOWLEDGEMENTS}

My thanks are due to Dr. J. K. E. Amorin, Directeur des Services Administratifs et Sanitaires, Togo, for permission to publish this paper, and to the Catholic Mission Sisters at Koloware leprosy village in northern Togo for their assistance. 


\section{REFERENCES}

I. MUir, E. (1948). Manual of Leprosy, Chapt. 3, E. \& S. Livingstone Ltd.

2. MOISER, B. (1946). Cockroaches and leprosy transmission. E. Afr. J., 6, June and Oct.

3. SPICKETT, s. G. (1961). A preliminary note of Demodex folliculorum Simon (1842) as a possible vector of leprosy. Lep. Rev., 32, 4, 263-268.

4. WEDDEL, G. and PALMER, ElizABETh (1963). The pathogenesis of leprosy: an experimental approach. Lep. Rev., 34, 2, 57-61.

5. Susman, I. A. (1963). The pattern of leprosy in the Gambia, West Africa. Lep. Rev., 34, 2, 83-94.

6. HORTON, R. J. and POVEY, SUSAN (1966). The distribution of first lesions in leprosy. Lep Rev., 37, 2, $113-114$.

7. Rogers, L. and muir, E. (1946). Leprosy, 3rd ed., pp. $165,73,207$.

8. Cochrane, R. G. (1947). A Practical Textbook of Leprosy, pp. 11, 13, 16, 21. London: Oxford University Press.

9. Doull, J. A. (1957). U.S. Veterans Bureau. Technical Bulletin of the Veterans Administration. (Medical Dept.), March 15, 1957.

10. Cha Ussinand, R. (1955). La Lèpre. Expansion Scientifique Française, 2nd ed.

11. монамеD ALi, P. (1964). The Age at Onset of Leprosy. Lep. Rev., 35, 4, 193-197.

12. languillon, J. (1965). La Lèpre. Cours des Infirmiers Specialistes en Léprologie. Institut Marchoux, Bamako.

13. BROWNe, s. G. (1965). The Age of Onset of Leprosy. Internat. J. Lep., 33, 3, 267-272.

14. spicketт, s.G. (1962). Genetics and the Epidemiology of Leprosy. Lep. Rev., 33, 2, 76-93, and $33,3,173-181$.

ADDENDUM

THE REPUBLIC OF TOGO

A decree was signed on July 21, 1966, by President Nicholas Grunitzky of the Republic of Togo creating in the service of the Ministry of Public Heath a 'Committee of Assistance to Leprosy Sufferers' (Comité d'Aide Aux Lépreux). This Committee includes the Minister of Public Health or his representative as President, and the following as members: the Minister of National Education or his representative, the Minister of Social Welfare or his representative, the Director of Public Health, the Chief of the Service of the Major Endemic Diseases, the Chief of the Service of the Anti-leprosy Campaign, and representatives of the Red Cross, Evangelical Mission, Catholic Mission and Moslem Community. The Committee is charged with the following functions in Togo:-
1. To find ways and means of coming to the aid of leprosy sufferers.

2. To sponsor the various anti-leprosy campaigns.

3. To supervise the distribution to the leprosy sufferers of gifts collected.

4. To provide for the social re-integration and rehabilitation of cured leprosy sufferers.

The Committee has already held two meetings under the chairmanship of the Minister of Public Health and to which the Leprologist, Dr. I. A. Susman, was invited to attend. The first meeting was in the way of an inaugural one to introduce members to each other and to outline the aims of the Committee. It also permitted the Leprologist the opportunity to draw attention to the present position with regard to leprosy in Togo and the problems encountered and envisaged.

The second meeting, also under the chairmanship of the Minister, was called to put before a large audience of representatives of many organisations concerned with welfare, charity, sport, arts, drama, crafts, etc., the draft of the programme of the anti-leprosy campaign leading up to the next World Leprosy Day in January, 1967. This was mainly to discuss ways and means of raising funds for the fight against leprosy. The programme included the formation of Regional Committees responsible to the central committee in Lomé, conferences and discussions throughout the country to medical and paramedical staff and to teachers, who would then give tallss to the general population and particularly to schoolchildren, film shows about leprosy, records to be made and played of traditional songs by leprosy patients, sermons in the various churches with leprosy as their theme on the two Sundays preceding World Leprosy Day. In addition, it was proposed to organise, throughout the country, dances, cinema shows, musical and theatrical concerts, fairs and tombola, football matches, boxing and basket-ball as well as making public collections.

On World Leprosy Day itself (which is normally the last Sunday in January) various activities would take place including appeals by 
the President of the Republic, by M. Raoul Follereau, founder of the Order of Charity and of World Leprosy Day (recorded) and by the Minister of Health. The distribution of gifts to the patients at the two leprosy villages and various treatment centres by a delegation of the Committee of Assistance to Leprosy Sufferers was also planned. The press and radio would be invited to take an active part in all these manifestations.

The anti-leprosy programme in Togo forms part of the Service of the Anti-yaws, Antileprosy and Anti-smallpox Campaign under the Ministry of Public Health. Until October, 1965, leprosy had been included in the campaign of the World Health Organisation directed principally against yaws and smallpox. Casefinding had been carried out by the teams of this campaign. Treatment for leprosy was available in all the hospitals and dispensaries throughout the country.

Since October, 1965, a Leprologist (Dr. I. A. Susman, formerly of the Gambia and Ghana) was assigned to Togo by the British Government under the British Bilateral Technical Assistance Scheme to Non-Commonwealth Countries in order to give a special priority to the leprosy problem.

It is estimated that there are 20,000 to 30,000 persons suffering from leprosy in Togoa prevalence of 10 to 20 per 1,000 . This is a high prevalence and it includes disabled and burnt-out patients and those still requiring to come under treatment.

Severe difficulties have been experienced in the campaign up till now because of lack of competent supervision by reason of absence of suitable means of transport for the supervising staff, who also have been insufficient in number.

It has been decided that a campaign founded on static clinies giving D.D.S. to as many patients as possible will be the most efficient method of approaching the problem in Togo. This arrangement will be an integral part of the general medical and health services, making use of the personnel already existing. The general supervision of the project, in addition to the Leprologist in charge, must be implemented by specially trained personnel (the 'contrôleurs-lèpre' or the 'agents-techniques').

Unicef are providing Mobylettes as a means of transport for these supervising staff.

Reorganisation of the two leprosy villages in existence (about 700 patients) and of all the treatment centres is at present in the process of being carried out. Stress is also being laid on propaganda and health education in the leprosy field by various means which include specially prepared posters, booklets and pamphlets.

It is hoped that in the near future it will be possible to carry out some sample surveys in several different regions of the country in order to obtain a better idea of the true pattern of leprosy in Togo than has been hitherto available. 